\title{
The Ability of Deaf Student in Solving Mathematics Problem
}

\author{
Samuel Igo Leton ${ }^{1}$, Wahyudin ${ }^{2}$, Darhim $^{3}$ \\ etonsamuel@gmail.com ${ }^{1}$ \\ Universitas Pendidikan Indonesia, Indonesia ${ }^{1}$, \\ Universitas Katolik Widya Mandira Kupang, Indonesia ${ }^{2}$
}

\begin{abstract}
The present study is aimed at describing and analyzing deaf student's ability of grade VIII in solving problem-related to social arithmetics. The research design used was a qualitative study with a case study. The number of subjects included was six students selected through purposive sampling from 3 schools, namely: 1 special school located in Nusa Tenggara Timur and 2 located in Central Java. From the analysis on work result and interview, subjects understood the problem by recognizing what was known and what was questioned, identifying elements which were recognized, correlating the information they obtained with the priorly formed knowledge, communicating their idea which is expressed through simple language and drawing, initial planning and implementing it using work strategy from behind to solve the problems, and checking the steps they used and became more ensured with the given answers.
\end{abstract}

Keywords: mathematical problem-solving ability, a deaf student, arithmetic problem.

\section{Introduction}

Deaf students are those having hearing impairment either partially or wholly which may cause complexity in their life. Deaf students commonly have a normal or average level of intelligence, however since intelligence development is highly affected by language development, so deaf students have low intelligence compared to normal students. This is due to difficulties in understanding language so deaf students rarely obtain information, of language, lack of vocabularies, difficult in understanding language expression containing metaphoric expression as well as abstract words. Consequently, deaf students need more time to learn to correlate mathematic concepts and use problem-solving[1], [2]. Understanding that language is one essential thing to solve a problem. There is a correlation between reading comprehension with the problem-solving ability [3]. Three abilities owned by deaf students related to the linguistic aspect of mathematics include: (a) intellectual skill including knowledge of the concept and structure and rules dealing with problem solving, (b) organized information in the form of schemata used in problem understanding, and (c) relevant strategy which is possible to be used by deaf students to solve problem [4]. Luckner and McNeill reported that deaf students face difficulty in solving the arithmetic problem and it is necessary to help them in developing that organizational and procedural skill. However, a visual ability that they have is very beneficial for deaf students in building understanding on a certain concept that they can solve problems [5]. Also, hearing impairment experienced by deaf 
students is not the direct cause of difficulty in learning mathematics. This is because not all deaf students do not have a better score than normal students; around 5\% of deaf students have average value or even above average in a standard test [6],[7]. From the explanation above, it can be noted that the objective of the present study is to reveal the ability of problem-solving related to social arithmetic in deaf students by exploring visual ability that they have.

\section{Research Methods}

This study uses a case study design to explore more deeply and detail the subject to be studied through various procedures to collect data. In collecting data, it provides problemsolving tests related to social arithmetic problems, conducting observations, and conducting in-depth interviews with the work. The number of the subjects in this study were six students who were selected through purposively in three schools: namely 2 subjects in SLB (Special School) in NTT and 4 SLB (Special School) subjects in Central Java. This research was carried out within 2 months of each school. The following are the problems given to the research subject.

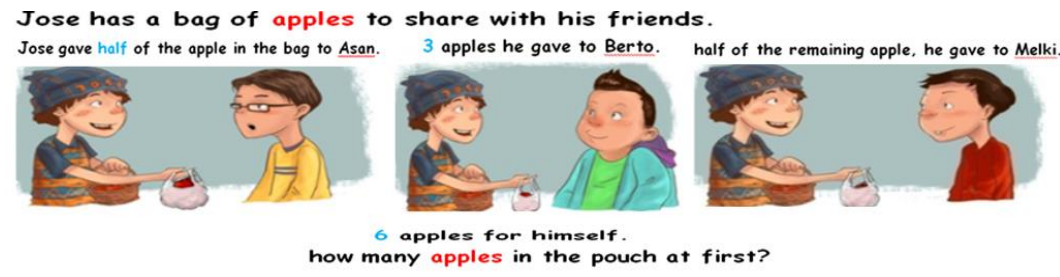

Fig 1. Illustration of deaf students to study mathematics

\section{Result Research}

There were several findings obtained by the researcher when the subject finished the test of problem-solving. The findings obtained than were described by the achievement indicator in the problem-solving steps as stated by Polya, as in Table 1. below.

Table 1. The indicator in the problem-solving

\begin{tabular}{|c|c|c|}
\hline No & Aspect & Indicators \\
\hline 1 & $\begin{array}{l}\text { Understanding the } \\
\text { problem }\end{array}$ & $\begin{array}{l}\text { a. Restate the problem into a language that is easier to understand } \\
\text { b. Identify the elements that are known to be asked }\end{array}$ \\
\hline 2 & Planning to solve & $\begin{array}{l}\text { a. Formulate everyday problems into mathematical models. } \\
\text { b. Determine the concept or principle of the problem given }\end{array}$ \\
\hline 3 & $\begin{array}{l}\text { Solving a problem by } \\
\text { the plan organized }\end{array}$ & $\begin{array}{l}\text { a. Bring up and choose approaches and ways of solving problems } \\
\text { b. Solve problems based on the approach and method that has been } \\
\text { determined. }\end{array}$ \\
\hline 4 & $\begin{array}{l}\text { Verifying the answer } \\
\text { correctness }\end{array}$ & $\begin{array}{l}\text { a. Check the match between answers that have been found and what } \\
\text { was asked. } \\
\text { b. Explain the truth of the answer }\end{array}$ \\
\hline
\end{tabular}




\subsection{Understanding Problem}

From the work result and interview, some information revealed that the six subjects in the present study were able to understand problems which were provided, To show the respective understanding of the subjects toward the problem, they made an illustration of the problems in the form of drawings. S1, S2, S3, S4, and S5 made drawings with round shape stating that a basket of apple and S6 made drawing with a rectangular shape. Additionally, the six subjects also re-stated understanding of the problem in a more simple language, that was "The apple in the basket is divided into two. Asan gets a half of the apple, Berto gets three apples. Melki gets the rest half, and Jose gets 6".

\subsection{Planing to solve}

In this stage, each subject had a various initial plan for solving the problem. From the interview result, it was found that the six subjects started the initial plan to solve the problem by making a drawing. Even though they had the same initial plan, the process and steps they took were different for each subject. S1 made a plan as shown in figure $\mathbf{1 .}$
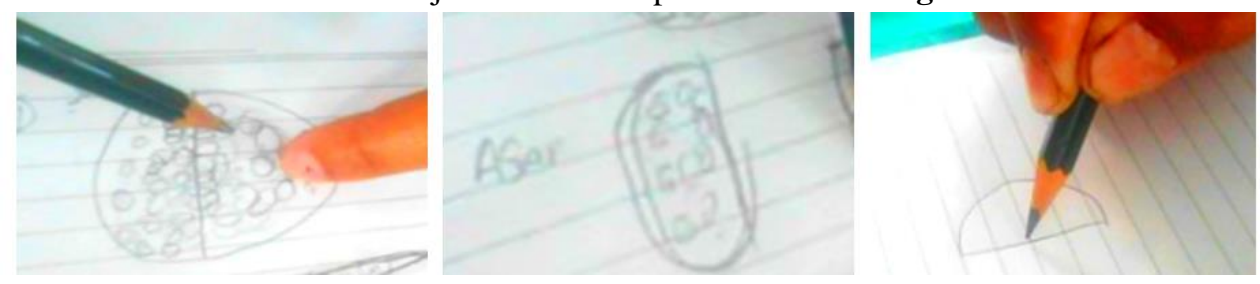

Fig. 2. Planning to solve by $\mathrm{S} 1$

S1 made little round shapes showing that the basket contained apples and divided it into two same parts. He made another half of circle showing that a half part was given to Erson. He also made another half circle showing the best part of the apple. S2, S3, S4, and S5 had the same initial plan that was by drawing a picture. Each subject started to draw a circle that symbolized a basket. The circle was then divided into two same parts. According to S2 that Jose gave a half of the apples in the basket to Asan and the remained a half part. Figure 2 showed S3 and S4 in making a solving plan, where S3 made a half of other circles showing that the best part of half apple in the basket. While S4 made two drawings of half circle and shaded one of the drawings then wrote the name of Asan. He also wrote a half circle drawing that he called as the rest.
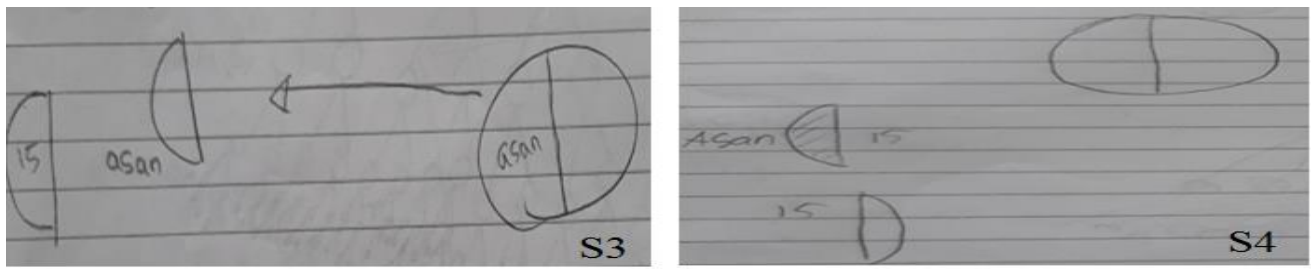

Fig. 3. Planning to solve by $\mathrm{S} 3$ and $\mathrm{S} 4$

S5 made drawing with circle shape and divided the circle area into two sample part and wrote 1/2 part for each area. He gave shading to 1/2 part and wrote Arsan. In 1/2 part which 
was not shaded, S5 wrote it like the rest. S6 made a rectangular shape and made lines dividing the rectangle into two same parts showing that the apples in the basket were divided into two same parts. He divided the rectangular are into two same parts and made shading $1 / 2$ part and wrote Arsan. In 1/2 part which was not shaded, he said "a half too" showing that there was still the rest of apple in the basket.

\subsection{Solving a problem by the plan}

Based on the data of the working result and interview result to the subject, the researcher found out that the six subjects implement their plan which was made to solve the problem. S1 run the plan by making line showing three apples were given to Berto as shown in figure 3 . He made the same half circle and lines showing three apples given to Berto and re-erased the lines and resulted in the rest three apples given to Berto. Then, he divided a circle area into two parts and wrote 6 in one part. He said that Melki also got 6 for an "a half" reason.
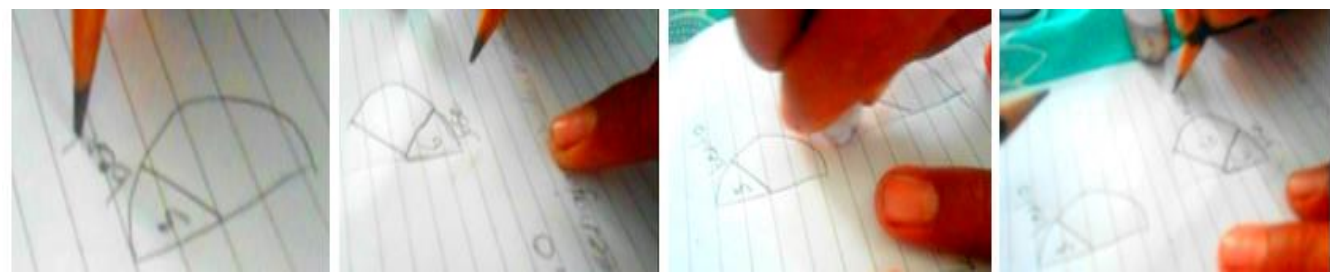

Fig. 4. Problem-solving made by S1

S1 summed the apples obtained by Melki, Jose, and Berto who got 15 . By which, he got the number of apple in the basket which was 30 apples. S2 run the plan by making lines showing three apples given to Berto as shown in figure 4. He said that there were remained apples in the basket. Then, S2 made a line dividing into two same parts. S2 wrote six apples for Jose. From the result of the interview, S2 gave the argument that "Melki has a half of that of Jose".
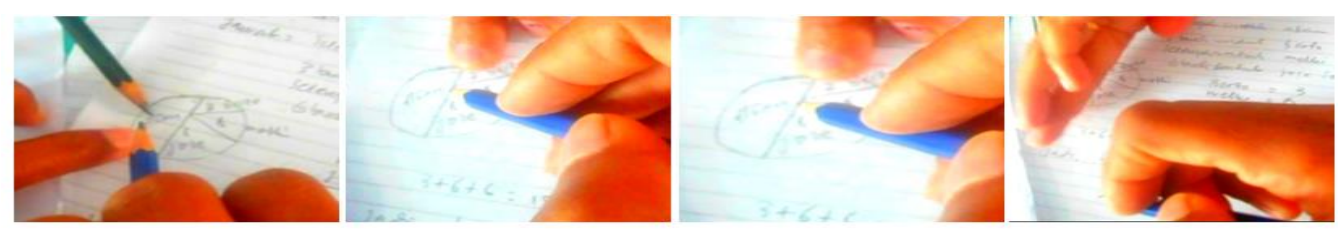

Fig. 5. Problem-solving made by S2

S2 summed the apple obtained by Melki, Jose, and Berto resulted in 15 . He wrote that 15 apples for Asan due to "a half part too" reason. S2 has managed information creatively to get the former number of apple in the basket, that was 30 apples. The procedure made by S3 was the same as that of S4. The two subjects run the plan by making lines showing three apples given to Berto of the rest of the part. According to S3, there were remaining apple in the basket. Then S3 made a line to divide it into two same parts and wrote six apples for Jose as 
shown in Figure 5. The two subjects also wrote 6 for Melki where according to S3 "it is the same." While according to S4 that "it is same, divided into two."
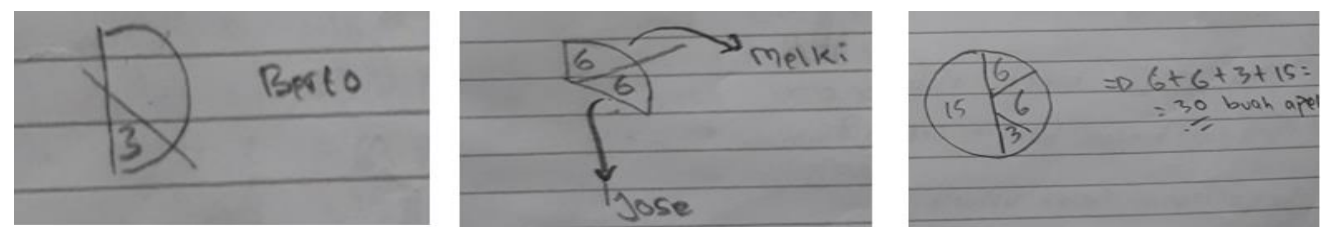

Fig. 6. Problem-solving made by S3

Then each subject summed apple obtained by Melki, Jose, and Berto that was 15 apples. Then S3 and S4 wrote 15 apples for Asan according to S3 due to "same" reason and according to S4 "same and divided into two." As the result, the number of apple in the basket was 30 apples.
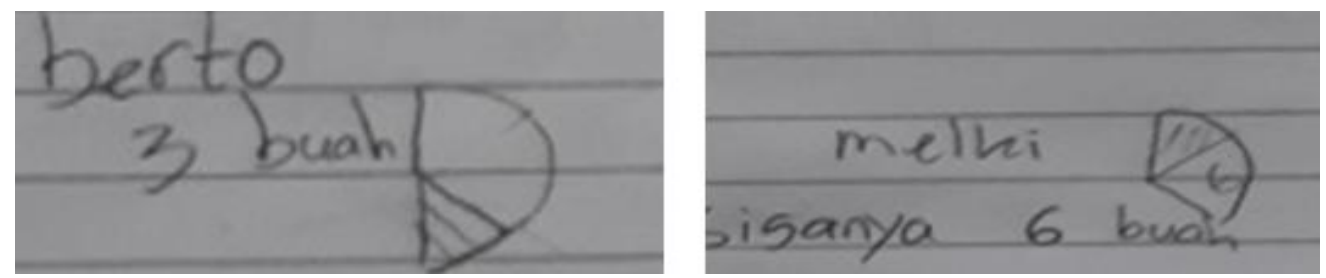

Fig. 7. Problem-solving made by S4

S5 run plan by making a line which divided a circle into two $1 / 2$ part which was not shaded and wrote 3 apples for Berto as shown in figure 6. He said that the rest of apple was divided into two, 6 for Jose, 6 for Melki under the "same" reason. Then, S5 summed apple obtained by Melki, Jose, and Berto and resulted from 16.
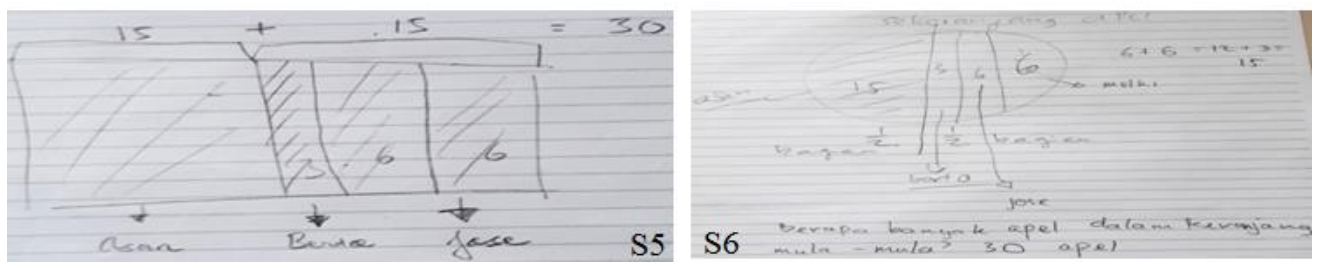

Fig. 8. Problem-solving made by S5 and S6

S6 acted the plan by making line dividing rectangle into two unshaded area and wrote three apples for Berto as shown in figure 7. Then he made a line to divide the unshaded area and wrote 6 for Jose and wrote 6 for Melki for "divided into two, a half" reason. Then, S6 summed apple obtained by Melki, Jose, and Berto and obtained 15. To obtain the number of apples given to Asan, S6 made elaboration that was by correlating information obtained 
previously and resulted in 15 apples for Asan due to "this is same, a half" reason that the number of apple in the basket was previously 30 apples.

\subsection{Checking the answer correctness}

To check the correctness of the answer, the six subjects re-check the steps taken in solving a problem. Then the researcher asked: what is wrong? For the question, the six subjects shook their head which means there was nothing wrong and they were sure with the answers.

\section{Discussion}

To express their understanding toward the given problem, the six subjects illustrated it by drawing. Representation of a problem in the form of the drawing represents all or part of the given problem [8]. Figure or graphic representation ability is the ability to translate mathematics problem into a drawing of graphic [9]. Moreover, the best mathematical ability owned by children who have a hearing impairment related to visual [10]. The six subject and deaf students, in general, represented their problem into visual form, and visual is very beneficial for deaf students [5]. From the interview result, it was revealed that drawing would ease the subjects to understand the abstract problem. To solve arithmetic problems, the deaf students conducted oral calculation and sign language which were simple arithmetic skill owned by deaf students [6], [11], [12]. The constraint that they have did not obstruct the six subjects in doing exploration through drawing. From the elaboration of the steps of problemsolving, the six subjects successfully implement the plan using a backward strategy to solve a problem. The six subjects made elaboration, that is correlating information obtained say for example divided into two, the rest of half part to obtain the number of apples given to Asan and Melki. Also, the researcher found out that to result from the former apple number, the six subjects implement one strategy in solving problem, that was a backward working strategy.

\section{Conclusion}

Based on the result of student's hearing impairment analysis in solving problems related to arithmetic-social concluded that deaf students can solve non-routine problem w where deaf student tend to visualize in the form of picture

\section{References}

[1] M. J. Peterson and S. Aller, “Arithmetic problem solving," J. Exp. Psychol., vol. 91, no. 1, pp. 93-97, 1971.

[2] P. Bryant, "Children and Arithmetic," J. Child Psychol. Psychiatry, vol. 36, no. 1, pp. 3-32, 1995.

[3] C. Serrano Pau, The Child and Solving Problems in Arithmetic. The Importance of 
Comprehensive Reading. American Annals of the Deaf, 1995.

[4] J. L. Luckner, Performance of a Group of Deaf and Hard-of-Hearing Students and Comparison Group of Hearing Students on a Series of Problems-Solving Tasks.

American Annals of the Deaf, 1994.

[5] M. C. Nunes T., An Intervention Program for Promoting Deaf Pupil's Achievement in Mathematics. OXFORD: Oxford University Press, 2002.

[6] D. W. ( Wood, The Mathematical Achievements of Deaf Children from Different Educational Environments. Britsh Journal of Educational Psychology, 1983.

[7] T. Nunes, ). Is Hearing Impairment a Cause of Difficulties in Learning Mathematics? In C. Donlan (Ed). Psychology Press, 1998.

[8] R. L. Ekawati, "Developing An Instrument For Measuring Of Teachers' Mathematics Content Knowledge On Ratio and Proportion: A Case Of Indonesian Primary Teachers," Int. J. Sci. Math. Educ., 2014.

[9] Kartini.., "Peran Representasi dalam Pembelajaran Matematika," Proseding Semin. Nas. Mat. dan Pendidik. Mat. UNY, pp. 36-372, 2009.

[10] T. Nunes, Teaching Mathematics to Deaf Children, LONDON. Whurr Publishers Ltd., 2004.

[11] M. Fayol, H. Abdi, and J. E. Gombert, "Arithmetic Problems Formulation and Working Memory Load,” Cogn. Instr., vol. 4, no. 3, pp. 187-202, 1987.

[12] W. Kintsch and J. G. Greeno, "Understanding and Solving Word Arithmetic Problems," Psychol. Rev., vol. 92, no. 1, pp. 109-129, 1985. 